\title{
PRELIMINARY NOTE ON THE TREATMENT OF GONORRHOEA WITH HEATED BOUGIES.
}

\author{
BY MAJORS L. W. HARRISON AND G. J. HOUGHTON. \\ Royal Army Medical Corps.
}

It is well known that the application of chemical antiseptics to the urethra fails to cure gonorrhoea because they do not reach the gonococci which are lying safely under the epithilium and within the numerous follicles and ducts which open into the urethra.

Another agent which is more penetrating and particularly destructive to the gonococcus is heat. Under artificial conditions the gonococcus is destroyed at a temperature of $104^{\circ} \mathrm{F}$. in six hours, and at higher temperatures in a considerably shorter time. Under natural conditions it is a common observation that when a patient suffering from gonorrhoea develops pyrexia from any cause the discharge frequently ceases, and numerous cases are now on record in which the onset of severe pyrexia brought the gonorrhoea to an abrupt termination. The experiments in which Finger, Ghon and Schlagenhaufer failed to infect with the gonococcus patients who were suffering from pyrexia are well known.

It is perhaps surprising that more advantage has not been taken of this weak spot in the armour of the gonococcus since, if the heat is gradually applied, patients can sustain in the urethra a temperature of $114^{\circ} \mathrm{F}$. to $119^{\circ} \mathrm{F}$. From experience, workers probably feared that the passage of an instrument along the acutely inflamed urethra would be rapidly followed by epiddidymitis.

The indirect application of heat by means of sitz-baths, which has been advocated by many, could hardly be expected to succeed owing to the large area of diffusion. By more direct methods, Kyaw (Med. Klin., November 10, 1912) has claimed considerable success from the use of diathermy, but this could have only a limited application owing to the great cost of necessary apparatus. In his later cases Kyaw has used a bougie through which hot water circulates, and claims even better results from it than with diathermy.

The use of water-heated bougies in the treatment of gonorrhoea was suggested to one of us (G.J.H.) some years ago by Dr. J. A. Valentine, of Silchar, and, following on a private discussion on methods of attacking the gonococcus, we decided to make a cautious trial of a bougie made on the same lines as that used by Dr Valentine, trusting that by keeping the patient under the influence of atropine no epididymitis would follow.
Briefly, this instrument consists of a silver catheter (No. 9 or 12 English), with no opening at its distal end; into it is passed another catheter (No. 2), which is open at both ends, the distal end being about an inch from the corresponding end of the enclosing catheter. The two tubes are soldered together at their proximal ends so as to make a watertight union, and the inner tube projects an inch or so from the outer. The latter is provided close to its proximal end with a short branch tube to lead away the water. The water from an irrigator flows down a suitable rubber tube (which is provided with a clip) to the inner metal tube of the instrument and is conducted by it almost to the distal end of the enclosing catheter, by which it returns to the branch tube; to this is attached another rubber tube to conduct the water to a bucket.

The treatment is applied as follows: On the previous evening and the same morning an antropine suppository (gr. 1/75) is administered, and before the bougie is passed the urethra is irrigated in the usual manner. The patient is then placed on a couch and adequately protected with a water-proof sheet. The sterilized and lubricated bougie is connected up to the rubber tubing leading from the irrigator, which is itself placed about 18 in. above the couch and filled with water at $114^{\circ} \mathrm{F}$. The bougie is then gently passed into the bladder and the clip opened to allow the water to flow from the irrigator. The temperature of the water in the irrigator is raised to $118^{\circ} \mathrm{F}$. by adding more hot water to it, and after a few minutes it is gradually raised in a similar manner to $121^{\circ} \mathrm{F}$ or $122^{\circ} \mathrm{F}$. After two or three more minutes the temperature of the water in the irrigator is again gradually raised to $125^{\circ} \mathrm{F}$, and this is maintained for five to ten minutes. At this temperature the outflowing water is generally $118^{\circ} \mathrm{F}$. At higher temperatures than this blistering of the meatus may follow.

There is naturally great discomfort when the bougie is first introduced, and the patient bears the maximum temperature with considerable difficulty, but after seeing the results in the first few cases all our patients have submitted willingly to the treatment.

We have also used for the same purpose an electrically-heated bougie devised for the treatment of urethral stricture by Dr. Ph. Kobelt (Munch. med. Woch., No. 30, 1912). With this instrument, which is provided with 
a thermometer, it is possible to regulate the temperature to a nicety so that it can be increased very gradually, but its cost is greater and, of course, it requires some source of electricity (accumulator or main), with a suitable resistance.

It is at present too early to state how frequently the treatment should be applied so as to obtain the best results. So far the bougie has generally been passed on two or three successive days and subsequent applications have been determined by clinical progress and the presence or otherwise of gonococci in the urethral discharge.

Results. - We have treated in this way sixteen cases, eleven acute, with profuse purulent discharge, and five subacute or chronic, with watery discharge, and have made many microscopical examinations of the urethral secretion; in all cases this contained numerous gonococci before the treatment was commenced. The most striking effect has been the rapid disappearance of the gonococci in most of the cases. In six (four of them acute), none could be found by the fourth day after the first application of the treatment; in two (one acute) they finally disappeared on the seventh day; in another (acute) they did not finally disappear until the eleventh day, but only a single pair could be found on the seventh day. In two cases (acute) massage of the anterior urethra on the fourth day failed to produce any secretion and no microscopical examination was made; in two (subacute) microscopical examination was inadvertently omitted until the sixth and thirteenth days respectively, when no discharge could be obtained. In three cases gonococci still persisted up to the time of writing. In one of these (acute) no gonococci were found on the seventh, but a few pairs on the fourteenth and nineteenth days. In the second, treatment was commenced on the twenty-first day in hospital, when three large peri-urethral infiltrates were present and an profuse purulent discharge in which gonococci swarmed; by the ninth day, the number of gonococci had greatly diminished, the discharge was very scanty and the infiltrates were the size of small shot. In the third case (acute) a few pairs only could be found on the sixteenth and no discharge could be obtained on the seventeenth day. As to other elements, the chief feature has been made an immediate increase of mucus and epithelium, the latter to a slight extent.

Clinically, in all cases the discharge has changed at once to muco-purulent or mucoserous. We did not expect it to cease rapidly after such treatment, but in six cases (four acute) it had disappeared before the eighth day, and in the remainder it was quite serious by this time. Stout was administered to all cases after disappearance of the discharge and caused no reappearance of symptoms. In contrast to the majority of gonorrhoea cases treated by routine methods, the prostate has remained normal to palpatation in all the early cases, and in other it had returned to normal. No case of epididymitis has occurred; on the contrary, a more recent case than those mentioned above a patient with subacute epididymitis on admission showed marked improvement on the day after the first application of the treatment.

Summary. - Our experience of this method of treating gonorrhoea is too recent to permit us to draw any definite conclusion as to its ultimate value, but we think the above results give grounds for hope that it will prove a distinct advance on other methods. So far it has not only proved quite free from danger as regards the production of complications, but such local gonococcal complications as we have met have been favourably influenced by it. The most favourable feature is its effect on gonococci, and it is reasonable to hope that with further experience and a more perfect technique we may destroy these and convert the gonorrhoea to a transient urethritis even more rapidly than we have yet succeeded in doing. Very possibly such a mild urethritis as remains after the gonococci have disappeared may prove no impediment to a soldier's discharge to duty. 